ISSN electrónico: 2172-9077

DOI: https://doi.org/10.14201/fjc202021267271

\title{
REFLEXIONES SOBRE EL PAPEL DEL CANON EN LAS ADAPTACIONES CINEMATOGRÁFICAS DE TEXTOS LITERARIOS
}

\section{Reflections on the Role of the Canon in Cinematographic Adaptations of Literary Texts}

\section{Dr. José Antonio PÉREZ BOWIE}

Catedrático (jubilado) de la Universidad de Salamanca (España)

bowie@usal.es

(iD) https://orcid.org/0000-0001-6987-1902

Fecha de recepción de la reseña: 22/07/2020

Fecha de aceptación definitiva: 28/07/2020

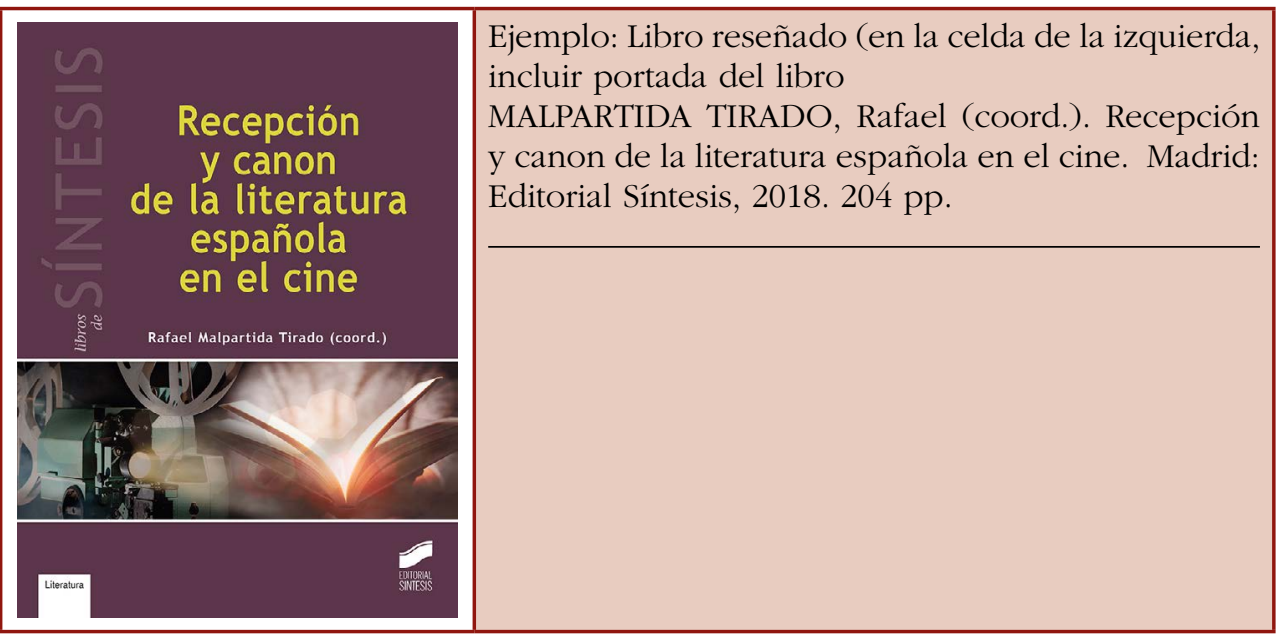

\section{Introducción}

En la cada vez más abundante producción bibliográfica en torno a las relaciones entre literatura y cine no son demasiados los títulos dedicados a cuestiones como los criterios que determinan la elección de un texto literario para ser traslado a la pantalla, la medida en que la valoración que merece el producto resultante pueda 
estar condicionada por su fidelidad a la obra originaria o hasta qué punto una película puede influir en la recepción del texto literario en que se basó. Son cuestiones que afectan a una parcela de los estudios literarios y artísticos como la de la recepción, que en las últimas décadas ha sido objeto de una atención creciente, tanto en el ámbito de la teoría literaria como en el del comparatismo, aunque en el caso concreto de los estudios filmo literarios no haya producido aportaciones de especial relevancia.

El libro que comento reúne ocho trabajos, en los que, de acuerdo con lo anunciado por el título, se tratan diversas cuestiones relacionadas con la recepción de algunas adaptaciones de textos literarios españoles llevadas a cabo por nuestra industria cinematográfico: el tratamiento de que ha sido objeto en la pantalla un subgénero como la novela de tema apocalíptico, la diversa acogida de que recibido ciertas adaptaciones tanto por la crítica especializada como por los públicos mayoritarios, los vínculos existentes entre una determinada película y la obra de algunos poetas contemporáneos, etc. Tales trabajos van encabezados por el que firma el coordinador del volumen, donde plantea los criterios metodológicos desde los que abordar la cuestión de la recepción de las adaptaciones de textos literarios a la pantalla, mientras que los restantes, centrados en el análisis de casos concretos se agrupan en tres secciones dedicadas respectivamente al tratamiento cinematográfico de textos narrativos, teatrales y poéticos.

En su amplio trabajo introductorio titulado «La recepción y en canon de la literatura en el cine: sugestiones y planteamientos", el coordinador, Rafael Malpartida, trata de deshacer algunos de los prejuicios sobre los que se ha sustentado la minusvaloración del cine frente a los textos literarios de los que a menudo se ha nutrido: el papel pasivo que en este último se atribuye al receptor, la idea de que el carácter colectivo de la creación cinematográfica impide la expresión personal del artista, la valoración de las adaptaciones en virtud de su fidelidad al texto originario o la recurrencia a criterios procedentes de la teoría literaria para juzgar las obras cinematográficas. Se detiene luego en las dificultades que plantea la configuración de un canon cinematográfico frente al literario, sustentado este último sobre una larga tradición academicista transmitida por las instituciones docentes mientras que aquel suele basarse en listas heterogéneas elaboradas desde la subjetividad de los encuestados y en las que, significativamente, tienden a ocupar los primeros lugares películas que han adaptado obras literarias de reconocido prestigio. Tras pasar revista a un amplio conjunto de criterios sobre la validez de las adaptaciones literarias en la pantalla y de comentar varias de ellas, concluye que la construcción de un canon de adaptaciones debería partir de «tasar méritos y deméritos en cada caso particular, sin partir a priori de lo que pueden conseguir o no conseguir la literatura o el cine», pues los logros de ambos se deben exclusivamente «a sus obras, no a supuestos y a abstracciones ya previstos en modelos taxonómicos y analíticos». Por ello, «la clave de una adaptación es que no se advierta dicha condición".

En la sección del libro dedicada a los trabajos sobre adaptaciones de textos narrativos, figura en primer lugar el de Lucía Morillo Herrero titulado «La recepción popular de la literatura y el cine apocalípticos en España: Fin y Extinction". Intenta reivindicar el género literario de la ciencia ficción, considerado habitualmente como subliteratura, lo que ha implicado también la exclusión del canon cinematográfico de las películas basadas en relatos pertenecientes a dicho género. Se centra en dos películas españolas recientes: Fin (Jorge Torregrosa, 2009; sobre la novela homónima de David Monteagudo) y Extinction (Miguel Ángel Vivas, 2015; sobre la novela Y pese a todo, 
de Juan de Dios Garduño), adscribibles a la corriente apocalíptica y que, a su entender, ofrecen un especial interés, porque superan la trivialidad argumental inherente al género planteando una temática de mayor hondura en la que se abordan problemas como las relaciones familiares, la soledad, o el enfrentamiento entre individuo y sociedad. El núcleo principal del trabajo lo constituyen sendos muestreos a través de las opiniones vertidas en las redes sociales para indagar en la recepción popular de ambas adaptaciones: el resultado es una calificación mayoritariamente desfavorable (una media de 4,7 para Extinction y de 3,6 para Fin) debida, según se concluye, a su alejamiento del arquetipo de película de ciencia-ficción apocalíptica.

Un intento similar de análisis de la recepción popular vemos en el artículo firmado por José Manuel Herrera Moreno y cuyo título es "La recepción popular de La pasión turca (Antonio Gala / Vicente Aranda»). El autor se ocupa de la adaptación que Aranda llevó a cabo de dicho texto y ubica a la película dentro del subgénero erótico género pues el director potencia el contenido sexual haciéndolo más explícito que en la novela y eliminando el suicido de la protagonista. El objetivo del trabajo es indagar en la respuesta del público y comprobar los índices de tolerancia ante ese tipo de productos. Tras revisar un conjunto de testimonios procedente de la crítica especializada y de usuarios de las redes sociales, constata que la opinión dominante es la insatisfacción por la falta de fidelidad a la novela y por la explicitud y sordidez de las escenas sexuales frente a la "poeticidad" de aquella.

El tercero de los artículos ("Cuando la literatura adapta al cine. La obra de Jacinto Molina y el reciclaje como estrategia de venta") se ocupa del subgénero de terror, aunque con un planteamiento inverso a los anteriores pues su objetivo es una novela de base cinematográfica: Alaric de Marnac (2009), escrita por Paul Naschy (seudónimo del actor, guionista y cineasta Jacinto Molina). El autor, Carlos Cuéllar Alejandro, analiza esta novela, que tiene como protagonista al aristócrata francés Gilles de Rais y demuestra que es el resultado de la reelaboración de tres guiones que el propio Molina escribió para otras tantas películas basadas en el sangriento personaje: $E l$ espanto surge de la tumba (Carlos Aured, 1972), El mariscal del infierno (León Klimovsky, 1974) y Latidos de pánico (dirigida por el propio Molina en 1982). Estudia los ajustes realizados para llevar a cabo la fusión de los tres relatos y su traducción a un medio distinto, se detiene en señalar la recurrencia a los diversos estilemas del género y considera la novela como un collage postmoderno con el que Molina, al final de su vida, hace un homenaje a su propio legado cinematográfico.

La sección dedicada a las adaptaciones de textos teatrales se abre con el artículo de Pablo Pérez Rubio "¿Primavera de mil flores o flores de otoño? Las adaptaciones teatrales en el cine de la Transición", que, como indica su título, no se limita al análisis de un caso concreto, sino que propone una panorámica general. Tras unas reflexiones iniciales sobre la relación entre cine y teatro sustentadas en el conocido trabajo de Susan Sontag, proporciona algunas de las razones explicativas del rechazo mostrado por el cine español hacia los textos teatrales durante los años de la Transición (la inercia de una tendencia observable ya en los últimos años del franquismo; el escaso interés de la industria por los nuevos comediógrafos, a excepción de Alfonso Paso; la inexplicable desatención hacia los dramaturgos hasta entonces vetados por la censura...) y comenta la anomalía de que el giro político producido en el país tras la muerte del dictador no conllevase un cambio en los modelos de adaptación de textos dramáticos vigentes. El núcleo del trabajo lo constituye la relación y comentario de las piezas teatrales trasladadas a la pantalla durante los años 1972-1981: señala el 
predominio abrumador de las adscribibles a la "comedia popular contra democrática", alimentada por viejos títulos pertenecientes un modelo teatral periclitado (de Muñoz Seca, Arniches) y otros debidos a los epígonos que continuaron cultivándolo (Alfonso Paso, Carlos Llopis, J.J. Alonso Millán, Santiago Moncada). En cambio, las películas que intentaron sintonizar con la nueva época se nutrieron fundamentalmente de la narrativa y solo muy esporádicamente acudieron a textos dramáticos: Luces de bohemia, Un hombre llamado Flor de Otoño y Las bicicletas son para el verano constituyen algunas de esas pocas excepciones.

El siguiente trabajo siguiente lleva por título "Lope de Vega como capital cultural. El caso de El perro del hortelano, de Pilar Miró» y lo firma Manuel España Arjona. Se inicia con una breve panorámica de las obras de Lope que han contribuido a configurar el canon actual del teatro áureo español, ofreciendo datos sobre las puestas en escenas de sus obras entre 1939 y 1989 y comparándolos con los de las noticias que se tienen de representaciones en épocas precedentes, para demostrar que la figura de Lope no gozó siempre de una valoración indiscutible. Pasa luego a analizar la repercusión que la adaptación de Pilar Miró ha tenido, a partir de su estreno, en la valoración de ese texto dramático tanto en el ámbito editorial como en el académico y en el teatral; una repercusión que ha afectado no solo a El perro... sino a otros textos de Lope cuyo número de ediciones de ha incrementado de modo notable. Considera que el éxito del filme de Miró se debió a su capacidad para empatizar con las expectativas del público español del momento, ofreciéndole «una comedia romántica sin aristas» cuya protagonista rompía con las estructuras clasistas que le impedían la libre elección de su destino. No obstante, este éxito no se repitió pues otro intento posterior, la adaptación de La dama boba por Manuel Iborra (2006), culminó en un fracaso. Lo que le lleva a concluir que el éxito de El perro... se debió a un cúmulo de circunstancias que van más allá del filme en sí.

La última sección del libro, "Poesía española y cine» contiene dos trabajos que difieren de los precedentes pues sus autores no se centran en ninguno de los filmes (por lo demás, poco abundantes) que pudieran considerarse adaptación de un texto poético, sino que se ocupan de dos casos que les permiten acercarse a otro tipo de vínculos entre la poesía y el cine.

Luis Bagué Quiles firma el titulado «Un canon adictivo: fantasmas, vampiros y cintas de vídeo", donde reflexiona sobre la relación contemporánea entre la imagen poética y la imagen fílmica. Partiendo de la hipótesis de que el influjo del cine sobre la poesía no ha consistido tanto en la traslación mimética de sus mecanismos compositivos sino en "la germinación asociativa de sus imágenes" y en "su facultad para generar una retícula de metáforas inéditas hasta entonces», pone en relación la mítica película Arrebato (Iván Zulueta, 1979) con la obra de los poetas Aníbal Núñez y Javier Egea para señalar sus coincidencias temáticas y el juego metafórico que comparten, desplegado en imágenes relativas al mundo de los estupefacientes, al vampirismo, a la casa tomada y al tránsito al otro lado del espejo. Pone de relieve cómo en el cineasta y en ambos poetas confluyen el compromiso político y la evasión a través de los paraísos artificiales e interpreta que, en los tres, la recurrencia de espectros, vampiros y fantasmas remite a "la identidad fragmentaria del sujeto contemporáneo y anticipa los estigmas de la dependencia, la infección y el aislamiento».

El volumen se cierra con el trabajo de Antonio Quesada Sánchez «El cine, la imagen de los creadores de la familia Panero y la recepción de su obra: notas sobre una percepción». Su propósito es mostrar cómo la película El desencanto (Jaime Chávarri, 
1976) y su secuela Después de tantos años (Ricardo Franco, 1994) influyeron notablemente en la percepción pública de los protagonistas, de tal modo que la imagen de estos difundida desde las pantallas cinematográficas es mucho más poderosa que la que ha podido transmitir la lectura de su obra poética. Ese efecto ha sido potenciado también por las entrevistas y las apariciones públicas de los tres hermanos; e, incluso, por las propias obras publicadas con posterioridad, en las que refuerzan su condición de "personajes». Quesada sostiene que la película de Chávarri contribuyó a crear esa imagen mientras que la de Ricardo Franco supuso su consolidación, pues en ella los protagonistas «se recrean» en unos personajes ya construidos no solo por El desencanto sino a través de los diversos canales mediante los que se mostraron en público.

En definitiva, nos encontramos ante un conjunto de acercamientos novedosos al ámbito de las relaciones entre la literatura y el cine, algunos de mayor interés y originalidad que otros, aunque todos ellos resultan estimables por su esfuerzo de proponer nuevos enfoques para abordar esa parcela de los estudios comparatistas y por las sugerencias que ofrecen para futuros trabajos. 
